\title{
Effect of Time of Artificial Insemination and Supplemental Estradiol on Reproduction of Lactating Dairy Cows
}

\author{
J. Hillegass, ${ }^{1}$ F. S. Lima, ${ }^{2}$ M. F. Sá Filho, and J. E. P. Santos ${ }^{3}$ \\ Department of Animal Sciences, University of Florida, Gainesville 32611
}

\begin{abstract}
Our objectives were to compare reproductive responses of dairy cows receiving timed artificial insemination (AI) either at 48 or $72 \mathrm{~h}$ after induction of luteolysis and supplemented or not with estradiol cypionate (ECP). Holstein cows (971) had their estrous cycles presynchronized with injections of $\mathrm{PGF}_{2 \alpha}$ at 37 and $51 \mathrm{~d}$ in milk (DIM) and then received an injection of $\mathrm{GnRH}$ at $64 \mathrm{DIM}$ and an injection of $\mathrm{PGF}_{2 \alpha}$ at 71 DIM. Cows were then assigned to a $2 \times 2$ factorial randomized block experiment; cows in the CoSynch $48 \mathrm{~h}$ (CoS48) received a final injection of GnRH concurrent with timed $\mathrm{AI} 48 \mathrm{~h}$ after $\mathrm{PGF}_{2 \mathrm{a}}$, whereas cows in the CoSynch $72 \mathrm{~h}$ (CoS72) received GnRH and timed AI 72 $\mathrm{h}$ after $\mathrm{PGF}_{2 \mathrm{a}}$. Half of the cows in each CoSynch protocol received an injection of $1 \mathrm{mg}$ of ECP $24 \mathrm{~h}$ after $\mathrm{PGF}_{2 \mathrm{a}}$. Therefore, the 4 treatments were as follows: CoS48NECP $(n=240), \operatorname{CoS} 72-\mathrm{NECP}(\mathrm{n}=246), \operatorname{CoS} 48$-ECP ( $\mathrm{n}$ $=245)$, and CoS72-ECP $(\mathrm{n}=240)$. Blood was sampled at $7 \mathrm{~d}$ before and at the first GnRH of the CoSynch from all cows for analysis of progesterone concentration in plasma. Cows were classified as anovular when progesterone was less than $1.0 \mathrm{ng} / \mathrm{mL}$ in both samples. Blood was also sampled during proestrus from a subset of 123 cows to measure concentrations of estradiol and at $7 \mathrm{~d}$ after timed AI to measure concentrations of progesterone. Ovaries from the same subset of 123 cows were examined by ultrasonography to determine ovulatory follicle diameter and incidence of ovulation. Pregnancy was diagnosed at 40 and $68 \mathrm{~d}$ after AI. Prevalence of cyclic cows was $72.4 \%$ and was similar among treatments. Concentrations of estradiol increased after ECP treatment and at $72 \mathrm{~h}$ of proestrus with CoS72. Pregnancy at 40 and $68 \mathrm{~d}$ after AI and pregnancy loss were not affected by timing of AI or supplemental ECP.
\end{abstract}

Received November 27, 2007.

Accepted July 26, 2008.

${ }^{1}$ Current address: Department of Animal Sciences, Cornell University, Ithaca, NY 14853.

${ }^{2}$ Current address: Department of Large Animal Clinical Sciences, University of Florida, Gainesville, FL 32610-0136.

${ }^{3}$ Corresponding author: jepsantos@ufl.edu
Delaying timed AI to $72 \mathrm{~h}$ and supplementation with ECP increased the proportion of cows displaying estrus at AI, and cows detected in estrus had increased pregnancy per AI associated with improved ovulation and increased postovulatory progesterone concentration. These results indicate that extending the proestrus by delaying timed AI from 48 to $72 \mathrm{~h}$ plus supplemental ECP, despite increased expression of estrus at timed AI, did not improve reproductive performance of lactating dairy cows at first AI.

Key words: dairy cow, estradiol, reproduction, timed artificial insemination

\section{INTRODUCTION}

Systematic breeding programs have been widely adopted by dairy herds for increased control of estrus and ovulation, particularly when estrous detection is faulty. Implementation of protocols based on GnRH and $\mathrm{PGF}_{2 \alpha}$ to induce follicle wave emergence and corpus luteum (CL) regression, respectively, has proven to be a practical and efficient means to increase insemination of eligible cows. When combined with an injection of GnRH 2 to $3 \mathrm{~d}$ after the $\mathrm{PGF}_{2 \mathrm{a}}$, ovulation was synchronized in approximately $85 \%$ of the cows within 28 $\mathrm{h}$ allowing for fixed-time AI (Pursley et al., 1995). This has been identified as the Ovsynch protocol, which is widely utilized for management of first postpartum AI as well as to resynchronize ovulation in previously inseminated cows diagnosed as not pregnant (Caraviello et al., 2006).

A method to improve the response to ovulation synchronization protocols is to alter the timing of the final GnRH injection and timed AI (Pursley et al., 1998; Peters and Pursley, 2003; Portaluppi and Stevenson, 2005). Pursley et al. (1998) observed maximum pregnancy per AI when cows received timed AI $16 \mathrm{~h}$ after the final GnRH injection of the Ovsynch. In contrast, insemination $16 \mathrm{~h}$ after the final $\mathrm{GnRH}$ requires management of cows twice the same day, which often is inconvenient and resisted by dairy producers. Because of such restriction, Portaluppi and Stevenson (2005) evaluated different moments of $\mathrm{GnRH}$ injection and AI and observed improved reproductive responses when 
cows received the final $\mathrm{GnRH}$ and timed $\mathrm{AI}$ at $72 \mathrm{~h}$ after $\mathrm{PGF}_{2 \mathrm{a}}$; however, research by others observed either no difference or a decrease in pregnancy per AI when cows received timed $\mathrm{AI}$ at 72 compared with $48 \mathrm{~h}$ after induced luteolysis (Sterry et al., 2007; Brusveen et al., 2008).

Insemination of cows concurrent with administration of $\mathrm{GnRH} 48 \mathrm{~h}$ after $\mathrm{PGF}_{2 \alpha}$ might create asynchrony between time of ovulation and capacitation of spermatozoa, because insemination in the first few hours after the onset of estrus has been suggested to result in decreased oocyte fertilization (Saacke et al., 2000). Pregnancy per AI was greatest for cows receiving AI between 4 and $16 \mathrm{~h}$ after the onset of estrus (Dransfield et al., 1998). On the other hand, when cows were induced to ovulate with $\mathrm{GnRH} 48 \mathrm{~h}$ after $\mathrm{PGF}_{2 \mathrm{a}}$, only a small proportion displayed signs of estrus at timed AI (Pancarci et al., 2002), which indicates that systemic concentrations of estradiol were not sufficiently high or they were of too short a duration to elicit behavioral estrus. In fact, when cows received estradiol cypionate (ECP) with (Sellars et al., 2006) or in place of $\mathrm{GnRH}$ (Pancarci et al., 2002; Stevenson et al., 2004) to induce ovulation, a greater proportion displayed estrus, which might be the result of increased concentrations of estradiol (Sellars et al., 2006). Synchronization of ovulation with $1 \mathrm{mg}$ of ECP increased pregnancy per AI compared with AI after a synchronized estrus (Cerri et al., 2004). Because cows in estrus at timed AI have improved fertility (Pancarci et al., 2002; Cerri et al., 2004; Galvão et al., 2004; Souza et al., 2007), it is prudent to suggest that methods that increase estradiol concentrations and display of estrus in timed AI protocols might improve fertility of dairy cows. This may be particularly important for the high-producing dairy cow, which seems to lack sufficient blood concentrations of estradiol to induce estrus, ovulation, and uterine priming because of inherently high metabolism and clearance of steroid hormones (Wiltbank et al., 2006).

It was hypothesized that extending the period of proestrus and delaying the time of AI from 48 to 72 $\mathrm{h}$ after induced luteolysis would increase plasma concentrations of estradiol, expression of estrus, and fertility of dairy cows. It was also hypothesized that supplemental estradiol would further enhance these responses, primarily in cows receiving timed AI at 48 $\mathrm{h}$ after induced luteolysis. Therefore, the objectives of this study were to compare estradiol concentrations, incidence of estrus, pregnancy per AI, and pregnancy losses for cows enrolled in the CoSynch protocol when injection of GnRH and timed AI were performed either at 48 or $72 \mathrm{~h}$ after induced luteolysis with or without supplemental estradiol as ECP.

\section{MATERIALS AND METHODS}

\section{Animals, Housing, and Diet}

Lactating Holstein cows (971) from a 5,600-cow dairy farm with a rolling herd average of $11,400 \mathrm{~kg} / \mathrm{cow}$ of $3.5 \%$ FCM were enrolled in this study. Cows were housed in free-stall barns with access to dirt lots. Pens housed 370 cows, and primiparous and multiparous cows were housed separately throughout the study. All lactating cows were fed once daily, in the morning, the same TMR that was formulated to meet or exceed the dietary requirements for a Holstein cow weighing 650 $\mathrm{kg}$ and producing $45 \mathrm{~kg} / \mathrm{d}$ of $3.5 \% \mathrm{FCM}$ when consuming $25 \mathrm{~kg} / \mathrm{d}$ of DM (NRC, 2001). During the study period, the TMR was composed of (DM basis) $12.0 \%$ alfalfa hay, $34.0 \%$ corn silage, $5.0 \%$ citrus pulp, $4.4 \%$ almond hulls, $21.2 \%$ steam-flaked corn, $5.0 \%$ whole cottonseed, $2.5 \%$ dried corn distillers grains, $3.4 \%$ canola meal, $3.4 \%$ soybean meal, $3.4 \%$ lignosulfonate-treated soybean meal, $0.7 \%$ beef tallow, and $5.0 \%$ of a premix containing a protein supplement, minerals, and vitamins. The chemical analysis of the TMR resulted in $91.2 \% \mathrm{OM}$, $17.1 \% \mathrm{CP}, 30.4 \% \mathrm{NDF}, 20.6 \% \mathrm{ADF}, 3.9 \%$ lignin, $5.2 \%$ crude fat, $38.5 \% \mathrm{NFC}, 0.63 \% \mathrm{Ca}, 0.41 \% \mathrm{P}, 0.36 \% \mathrm{Mg}$, $1.32 \% \mathrm{~K}, 0.29 \% \mathrm{~S}, 0.34 \% \mathrm{Na}$, and $0.29 \% \mathrm{Cl}$.

\section{Treatments, Detection of Estrus, and Al}

Weekly, a new cohort of as few as 78 to as many as 132 cows at $37 \pm 3$ DIM was randomly assigned to one of the 4 treatments arranged as a $2 \times 2$ factorial, with a CoSynch $48(\mathrm{CoS} 48)$ and $72 \mathrm{~h}(\mathrm{CoS} 72)$ with (ECP) or without supplemental ECP (NECP; Figure 1). Because cows were enrolled once weekly, activities were performed at a specific day postpartum $\pm 3 \mathrm{~d}$, unless indicated otherwise. All cows received an injection of $25 \mathrm{mg}$ of $\mathrm{PGF}_{2 \alpha}$ (dinoprost tromethamine; $5 \mathrm{~mL}$ of Lutalyse Sterile Solution, Pfizer Animal Health, New York, NY) at 37 and 51 DIM for presynchronization of estrous cycles (Moreira et al., 2001). Beginning $13 \mathrm{~d}$ later, at 64 DIM, cows received one of 4 treatments: CoS48-NECP ( $\mathrm{n}=240$ ), an i.m. injection of $100 \mu \mathrm{g}$ of $\mathrm{GnRH}$ (gonadorelin diacetate tetrahydrate; $2 \mathrm{~mL}$ of Cystorelin, Merial Ltd., Iselin, NJ), followed by an injection of $\mathrm{PGF}_{2 a} 7 \mathrm{~d}$ later and a final injection of GnRH at timed AI $48 \mathrm{~h}$ after $\mathrm{PGF}_{2 \alpha}$ injection (Figure 1); CoS72-NECP ( $\mathrm{n}=246$ ), same as CoS48-NECP but with the final injection of $\mathrm{GnRH}$ and timed AI $72 \mathrm{~h}$ after $\mathrm{PGF}_{2 \alpha}$ injection; CoS48-ECP $(\mathrm{n}=245)$, same as CoS48-NECP but with an injection of $1 \mathrm{mg}$ of ECP (0.5 $\mathrm{mL}$ of ECP, Pfizer Animal Health, New York, NY) $24 \mathrm{~h}$ after $\mathrm{PGF}_{2 \alpha}$ injection; and CoS72-ECP $(\mathrm{n}=240)$, same 


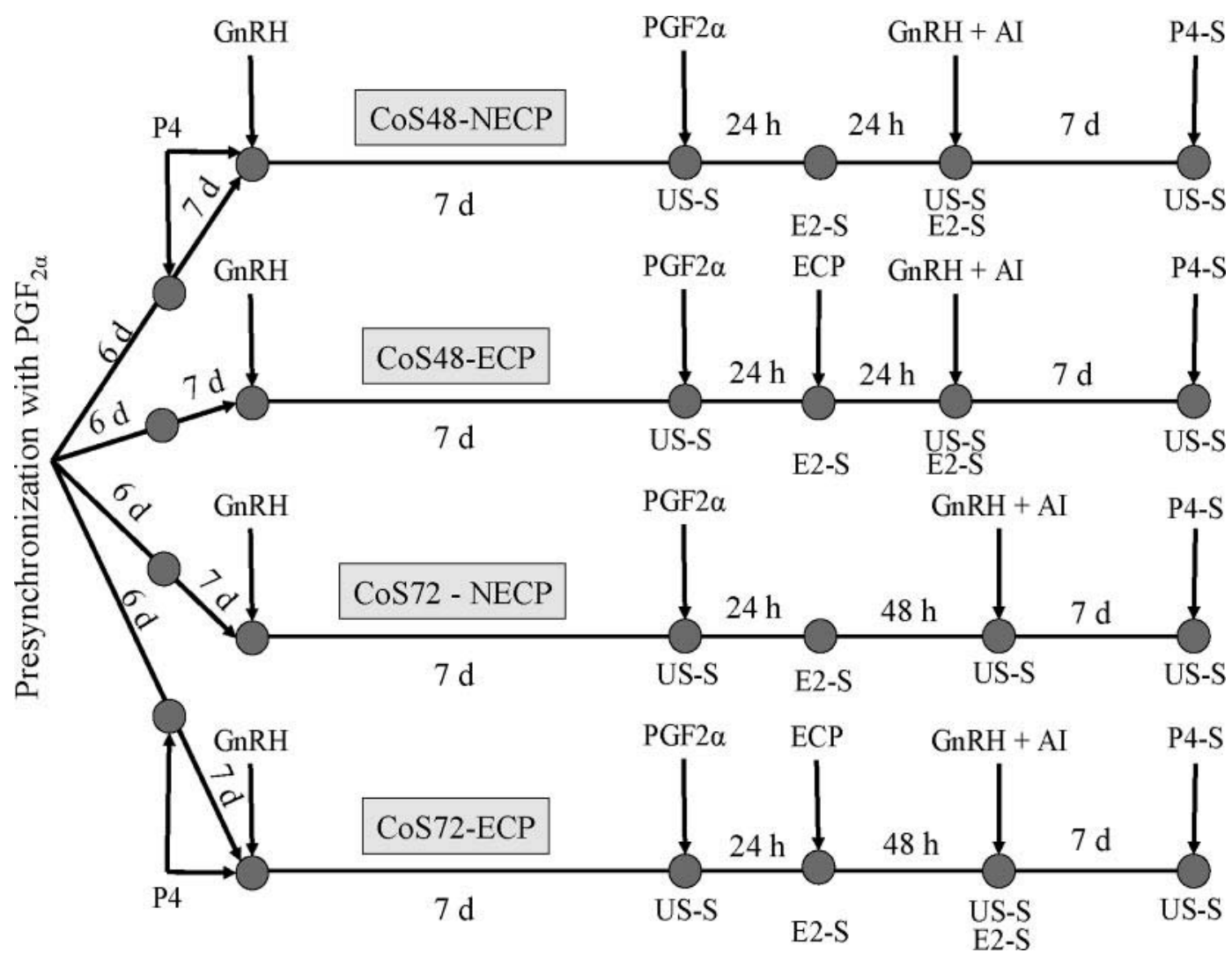

Figure 1. Diagram of activities during the study. All cows received 2 injections of $25 \mathrm{mg}$ of $\mathrm{PGF}_{2 \alpha} 14 \mathrm{~d}$ apart (presynchronization), with the second injection given $13 \mathrm{~d}$ before initiating one of the 4 treatments. Treatments were CoSynch $48 \mathrm{~h}$ without estradiol cypionate (CoS48NECP), CoSynch $48 \mathrm{~h}$ with estradiol cypionate (CoS48-ECP), CoSynch $72 \mathrm{~h}$ without estradiol cypionate (CoS72-NECP), CoSynch $72 \mathrm{~h}$ with estradiol cypionate (CoS72-ECP). ECP = injection of $1 \mathrm{mg}$ of estradiol cypionate; E2-S = blood sampling for analysis of estradiol in a subgroup of 123 cows; GnRH = injection of $100 \mu \mathrm{g}$ of GnRH; P4 = blood sampling for analysis of progesterone; P4-S = blood sampling for analysis of progesterone in a subgroup of 123 cows; $\mathrm{PGF}_{2 a}=$ injection of $25 \mathrm{mg}$ of $\mathrm{PGF}_{2 a}$; US-S = ultrasonographic examination of ovaries in a subgroup of 123 cows.

as CoS72-NECP but with an injection of $1 \mathrm{mg}$ of ECP $24 \mathrm{~h}$ after $\mathrm{PGF}_{2 \mathrm{a}}$ injection.

All inseminations were performed once daily, in the morning by 2 technicians. After the $\mathrm{PGF}_{2 \alpha}$ injection of the CoSynch, cows had their tail heads painted using paintsticks (All-weather Paintstik, LA-CO Industries, Chicago, IL), and cows with removed tail head paint were considered to be in estrus. Throughout the manuscript, detection of estrus refers only to removal of tail head paint, and information on whether the cow was in estrus at the time of AI was recorded. Cows assigned to CoS72 that had tail paint removed at $48 \mathrm{~h}$ after the $\mathrm{PGF}_{2 \mathrm{a}}$ injection were inseminated that same morning. Semen from 8 different sires was randomly assigned to the synchronization protocols to maintain similar distributions of sires across treatments.

After the first AI, cows observed with tail head paint removed were reinseminated. Cows with an interinsemination interval between 5 and $17 \mathrm{~d}$ after the first AI were considered to have short-cycled.

\section{Blood Sampling, Progesterone Analysis, and Evaluation of Cyclic Status}

Blood samples ( 8 $\mathrm{mL})$ were collected from all cows $7 \mathrm{~d}$ before and again at the first GnRH of the CoSynch protocols, which corresponded to 57 and 64 DIM, by puncture of the median coccygeal vein or artery using evacuated tubes (Becton Dickinson, Franklin Lakes, NJ) containing $\mathrm{K}_{2}$ EDTA for plasma separation. Samples were immediately placed in ice and transported to the laboratory within $5 \mathrm{~h}$ of collection. Blood tubes were centrifuged at $1,500 \times \mathrm{g}$ for $15 \mathrm{~min}$, and plasma was frozen at $-25^{\circ} \mathrm{C}$ until analyses.

Analysis of concentrations of progesterone in plasma was performed by ELISA as described previously (Cerri et al., 2004). A plasma sample containing $2.5 \mathrm{ng} /$ $\mathrm{mL}$ was analyzed in every microplate and was used to determine the interassay CV. The intra- and interassay CV were 5.2 and $12.1 \%$, respectively. Cows having plasma progesterone concentration $\geq 1.0 \mathrm{ng} / \mathrm{mL}$ in ei- 
ther sample were classified as cyclic, and cows having plasma progesterone concentrations $<1.0 \mathrm{ng} / \mathrm{mL}$ in both samples were classified as anovular.

\section{Analyses of Estradiol During CoSynch and Progesterone $7 \mathrm{~d}$ After Timed Al}

Blood samples were collected as described above from a subset of 123 cows $(\mathrm{CoS} 48-\mathrm{NECP}=27$; CoS48$\mathrm{ECP}=28$; CoS72-NECP $=39$; and CoS72-ECP $=29)$ at 48 and $72 \mathrm{~h}$ after the $\mathrm{PGF}_{2 \alpha}$ injection of the CoSynch (73 and 74 DIM) and at $7 \mathrm{~d}$ after the final GnRH of synchronization protocols, at 80 and 81 DIM for cows in the CoS48 and CoS72, respectively. Blood samples collected at 48 and $72 \mathrm{~h}$ after the $\mathrm{PGF}_{2 \alpha}$ injection of the CoSynch protocols, which corresponded to 24 and $48 \mathrm{~h}$ after treatment with ECP, respectively, were analyzed for concentrations of estradiol by a double-extraction RIA according to Perry et al. (1991). Samples were analyzed in duplicates in a single assay, and the CV was $11.1 \%$. Samples with CV $>15 \%$ between the duplicates were reanalyzed in a second assay. Samples collected $7 \mathrm{~d}$ after the final $\mathrm{GnRH}$ injection and timed $\mathrm{AI}$ in the CoSynch protocols were analyzed for progesterone concentrations as described previously to determine possible differences between treatments during early diestrus.

\section{Ultrasonographic Examination of the Ovaries}

The same subset of cows in which plasma was analyzed for estradiol $(\mathrm{CoS} 48$-NECP $=27$; CoS48-ECP $=$ 28; CoS72-NECP = 39; and CoS72-ECP = 29) had their ovaries examined by transrectal ultrasonography (Sonovet 2000, Universal Medical Systems, Bedford Hills, $\mathrm{NY}$ ) using a $7.5-\mathrm{MHz}$ linear probe concurrent with the $\mathrm{PGF}_{2 \alpha}$ of the CoSynch protocols, again at AI, and $7 \mathrm{~d}$ later. Maps of both ovaries of cows were drawn, and diameter and location of follicles $>8 \mathrm{~mm}$ and CL were recorded to determine diameter of ovulatory follicle and incidence of single and double ovulations.

\section{Pregnancy Diagnosis}

All cows were examined for pregnancy by palpation per rectum of the uterus and its contents for detection of an embryonic vesicle at $40 \pm 1 \mathrm{~d}$ after AI, and pregnant cows were reexamined 4 wk later at $68 \pm 1 \mathrm{~d}$ after AI. Cows initially diagnosed as pregnant on d 40 after $\mathrm{AI}$ and found nonpregnant $4 \mathrm{wk}$ later were considered to have experienced pregnancy loss. Pregnancy per AI was defined as the number of pregnant cows divided by the number of inseminated cows within each treatment at 40 and $68 \mathrm{~d}$ after $\mathrm{AI}$.

\section{BCS and Milk Yield}

Cows were scored for body condition ( $1=$ emaciated; 5 $=$ obese) on the day of the first $\mathrm{PGF}_{2 \alpha}$ of the presynchronization at $37 \mathrm{DIM}$ and again during the week of $\mathrm{AI}$ at the $\mathrm{PGF}_{2 \alpha}$ of the CoSynch protocols at 71 DIM using the method described by Ferguson et al. (1994) as depicted in the Elanco Animal Health BCS chart (Elanco Animal Health, 1996). For purpose of analyses of the effects of BCS on prevalence of anovular cows, detection of estrus, pregnancy per AI, and pregnancy loss, cows were classified according to BCS change from 37 to 71 DIM as having lost, maintained, or gained body condition and according to BCS at 71 DIM as low if BCS was $\leq 2.50$, moderate if BCS was 2.75 to 3.0 , and high if $\mathrm{BCS} \geq 3.25$.

Yields of milk were recorded daily for individual cows during the first $70 \mathrm{~d}$ postpartum to determine the effect of milk yield on the reproductive outcomes evaluated. For purposes of analysis, yields of milk were included in the statistical models for individual cows either as the average for the first $10 \mathrm{wk}$ postpartum or the average for the week of AI. The latter was used for analysis of incidences of ovulation and of double ovulation. In both cases, milk yield was categorized into quartiles. Yields of milk $( \pm \mathrm{SD})$ for each quartile in the first 10 wk postpartum were as follows: quartile $1=21.8 \pm 3.8$ $\mathrm{kg} / \mathrm{d}$; quartile $2=28.9 \pm 1.2 \mathrm{~kg} / \mathrm{d}$; quartile $3=32.3 \pm 1.1$; and quartile $4=37.6 \pm 2.7 \mathrm{~kg} / \mathrm{d}$ for primiparous cows and quartile $1=30.5 \pm 5.9 \mathrm{~kg} / \mathrm{d}$; quartile $2=39.5 \pm 1.4$ $\mathrm{kg} / \mathrm{d}$; quartile $3=44.6 \pm 1.6$; and quartile $4=50.1 \pm 2.7$ $\mathrm{kg} / \mathrm{d}$ for multiparous cows.

\section{Experimental Design and Statistical Analyses}

The experimental design was a randomized block with treatments arranged as a $2 \times 2$ factorial. Weekly, a cohort of cows at $37 \pm 3$ DIM was blocked by parity (primiparous and multiparous), BCS, and milk production in the first month of lactation, and, within each block, each cow was randomly assigned to 1 of 4 treatments.

Based on previous studies, we expected that delaying the final injection of $\mathrm{GnRH}$ and timed $\mathrm{AI}$ to $72 \mathrm{~h}$ after the $\mathrm{PGF}_{2 \alpha}$ of the CoSynch would increase pregnancy per AI 8 percentage points (Portaluppi and Stevenson, 2005). Likewise, we anticipated that addition of ECP would enhance pregnancy per AI by 8 percentage points (Cerri et al., 2004). Therefore, the sample size was calculated to provide sufficient experimental units per main treatment factor in the model (time of AI and ECP) for significance $(\alpha=0.05 ; B=0.20)$ when a 6 -percentage point difference in pregnancy per $\mathrm{AI}$ was 
observed, given that pregnancy per AI would range from 30 to $45 \%$.

Dichotomous outcomes were analyzed using the LOGISTIC procedure of SAS (SAS/STAT, version 9.1, SAS Institute Inc., Cary, NC). All models included the effects of time of AI (CoS48 and CoS72), supplemental estradiol (ECP and NECP), and interaction between time of AI and supplemental estradiol. In addition, univariate analyses were performed for covariates such as parity (primiparous and multiparous), cyclic status (anovular and cyclic), BCS change from d 37 to AI (lost, maintained, or gained BCS), BCS at AI, and milk yield (either as a continuous variable or also categorized into quartiles), and those found to be significant $(P<0.10)$ were included in the multivariate logistic model with respective interactions with time of AI and supplemental estradiol. Because univariate analysis resulted in similar reproductive responses to milk yield when analyzed as a continuous variable or categorized into quartiles, the latter was chosen to generate frequency tables. For pregnancy responses, sire and expression of estrus were also included in the logistic regression models. The final logistic regression model removed variables by a backward elimination based on the Wald's statistics criterion when $P>0.10$. Adjusted odds ratios (AOR) and 95\% confidence intervals (CI) were calculated. Display of estrus at different intervals after $\mathrm{PGF}_{2 a}$ was also analyzed by logistic regression as described above. At $48 \mathrm{~h}$ after $\mathrm{PGF}_{2 \mathrm{a}}$, those cows already observed in estrus at $24 \mathrm{~h}$ were not included in the analysis. Similarly, at $72 \mathrm{~h}$ after $\mathrm{PGF}_{2 \mathrm{a}}$, those cows already observed in estrus at 24 and $48 \mathrm{~h}$ were not included in the analysis.

Detection of estrus and pregnancy per AI were also analyzed for the subgroup of cows in which ovulation and progesterone concentrations on $\mathrm{d} 7$ after timed AI were evaluated. Cows were classified based on progesterone concentrations on $\mathrm{d} 7$ as having a low, moderate, or high concentration when concentrations were $<1 \mathrm{ng} /$ $\mathrm{mL}$, between 1.0 and $1.79 \mathrm{ng} / \mathrm{mL}$, and $\geq 1.80 \mathrm{ng} / \mathrm{mL}$, respectively. Cows were categorized as having small or large ovulatory follicles if the ovulatory follicle was less than or $\geq 15 \mathrm{~mm}$ in diameter, respectively. The effect of double ovulation on pregnancy was also evaluated. The logistic regression model included the effects of time of AI (CoS48 and CoS72), supplemental estradiol (ECP and NECP), and interaction between time of $\mathrm{AI}$ and supplemental estradiol and each of the other explanatory variables of interest (progesterone concentration, size of ovulatory follicle, and double ovulation).

Diameter of the ovulatory follicle and concentrations of progesterone after AI were analyzed by the GLM procedure of SAS (SAS/STAT, version 9.1, SAS Institute Inc.), and models included the effects of time of AI
(CoS48 and CoS72), supplemental estradiol (ECP and $\mathrm{NECP}$ ), and interaction between time of AI and supplemental estradiol. Additional covariates were included as found appropriate. Concentrations of estradiol in plasma were analyzed by the MIXED procedure of SAS (SAS/STAT, version 9.1, SAS Institute Inc.) with the effects of time of AI (CoS48 and CoS72), supplemental estradiol (ECP and NECP), interaction between time of AI and supplemental estradiol, hour at blood sampling, parity, detection of estrus, interaction between time of AI and hour, interaction between supplemental estradiol and hour, and interaction between time of $\mathrm{AI}$ and supplemental estradiol and hour. Cow nested within the interaction of time of AI and supplemental estradiol was the random error in the model. The covariance structure with the smallest Schwartz Bayesian criterion was chosen for the REPEATED statement in the mixed model. Treatment differences with $P \leq 0.05$ were considered significant, and $0.05<P \leq 0.10$ was designated as a tendency to differ.

\section{RESULTS}

As expected, the median and mean lactation number did not differ $(P=0.97)$ among treatments and were 1 and $1.2 \pm 0.03$, respectively. Similarly, milk yield in the first $70 \mathrm{~d}$ postpartum was similar $(P>0.20)$ for cows in the CoS48 and CoS72 and those supplemented or not with ECP, and milk yields averaged $41.1 \pm 0.52$ and $30.1 \pm 0.23 \mathrm{~kg} / \mathrm{d}$ for multiparous and primiparous cows, respectively. Median and mean BCS were similar $(P>$ 0.20 ) among treatments and were 3.25 and $3.22 \pm 0.01$, respectively.

The prevalence of cyclic cows at $64 \mathrm{DIM}$ was $72.4 \%$, and cyclicity was not equally balanced among treatments (Table 1). For cows in the CoS48, those supplemented with ECP had lower prevalence of cyclicity, whereas for cows in the CoS72, those not supplemented with ECP experienced a lower prevalence of cyclicity. Cyclic status was influenced by parity, with multiparous cows being 1.6 times more $(P=0.04)$ likely to be cyclic than primiparous cows. Similarly, BCS at AI influenced $(P<$ 0.001) cyclic status, and for cows classified with BCS as low, moderate, and high, the prevalence of cyclic cows was 53.6, 69.1, and $77.1 \%$, respectively. In fact, BCS at AI for cyclic cows was greater $(P<0.001)$ than that of anovular cows (3.30 vs. 3.11).

Concentrations of estradiol were similar between the CoSynch protocols, but cows receiving ECP had increased $(P=0.005)$ concentrations at 48 and $72 \mathrm{~h}$ after induction of luteolysis (Figure 2). Interestingly, an interaction $(P=0.007)$ between CoSynch and hour of blood sampling was observed, because cows receiving $\mathrm{CoS} 48$ experienced a decline in concentrations of 
estradiol, from 5.11 to $3.09 \mathrm{pg} / \mathrm{mL}$ between 48 and 72 $\mathrm{h}$, whereas cows receiving the CoS72 maintained estradiol concentrations (4.90 and $4.17 \mathrm{pg} / \mathrm{mL}$ at 48 and 72 $\mathrm{h}$, respectively). Concentrations of estradiol were maintained in cows in the CoS72, because those receiving CoS72-NECP did not experience a decline in plasma estradiol between 48 and $72 \mathrm{~h}$ after induction of luteolysis. Nevertheless, the interaction between CoSynch and ECP and hour was not significant $(P=0.11)$.

Expression of estrus increased $(P<0.0001)$ with delaying time of AI from 48 to $72 \mathrm{~h}$, as well as with supplemental ECP (Table 1). Estrus was observed in $64.5 \%(313 / 485)$ of cows after the CoS72 compared with $46.5 \%$ (226/486) cows in the CoS48. Of the cows that received ECP, 69.8\% (337/483) displayed estrus compared with $41.4 \%$ (202/488) of cows not receiving ECP. Regardless of treatment, the majority of cows observed in estrus were detected $72 \mathrm{~h}$ after injection with $\mathrm{PGF}_{2 \alpha}$ (Figure 3). It is clear that treatment with ECP increased expression of estrus but only at $72 \mathrm{~h}$ or $48 \mathrm{~h}$ after ECP injection. Expression of estrus increased $(P=0.04)$ in parallel to increases in BCS at $\mathrm{AI}$, and they were $41.2,50.4$, and $60.3 \%$ for cows with $\mathrm{BCS}$ at $\mathrm{AI} \leq 2.50,2.75$ to 3.00 , and $\geq 3.25$, respectively. In addition to treatment and BCS at AI, only parity influenced estrous expression, and primiparous cows were 2.6 times more likely $(\mathrm{AOR}=2.58 ; 95 \% \mathrm{CI}=1.72$, 3.88 ) to be detected in estrus than multiparous cows (59.6 vs. $35.0 \% ; P<0.001$ ).
Short-cycling was not influenced by CoSynch or supplemental ECP (Table 1). Approximately 5.3\% of the cows in the study returned to estrus between 5 and 17 $\mathrm{d}$ after the first AI. Short-cycling was not influenced ( $P$ $>0.10$ ) by BCS at AI, BCS change from enrollment to AI, milk yield, and parity of cows. In contrast, anovular cows were 2.6 times more $(\mathrm{AOR}=2.59 ; 95 \% \mathrm{CI}=1.44$, 4.66) likely to have premature return to estrus than cyclic cows (3.9 vs. $9.1 \% ; P=0.002)$. Cyclic cows $(27.9$ \pm 0.8 vs. $24.4 \pm 1.0 \mathrm{~d} ; P<0.001)$, and cows observed in estrus (27.1 \pm 0.9 vs. $25.3 \pm 0.8 \mathrm{~d} ; P=0.07)$ had longer intervals between AI.

Pregnancy per AI at 40 and 68 d after AI did not differ among treatments, and at $40 \mathrm{~d}$ after AI, they were 44.0 and $44.7 \%$ for CoS48 and CoS72, respectively, and 43.4 and $45.3 \%$ for NECP and ECP cows, respectively (Table 1). For cows in CoS72, 38 of 485 were inseminated before $72 \mathrm{~h}$ because they were in estrus, 2 cows at $24 \mathrm{~h}$ after $\mathrm{PGF}_{2 \alpha}$ and 36 at $48 \mathrm{~h}$ after $\mathrm{PGF}_{2 \mathrm{a}}$. Pregnancy per AI at $40 \mathrm{~d}$ for CoS72 cows inseminated before $72 \mathrm{~h}$ was $55.3 \%$ (21/38), and it did not differ $(P=0.18)$ from that of cow timed AI at 72 h $(43.9 \%, 196 / 447)$. Pregnancies per AI at $40 \mathrm{~d}$ after insemination increased $(P=0.02)$ with increasing BCS at $\mathrm{AI}$, and they were $24.7,43.0$, and $48.3 \%$ for cows with $\mathrm{BCS} \leq 2.50,2.75$ to 3.00 , and $\geq 3.25$, respectively. Cyclic cows were 1.85 times more $(P<0.0001)$ likely to become pregnant than anovular cows (48.8 vs. $32.8 \%)$. Likewise, primiparous cows $(P=0.04)$ had increased

Table 1. Effect of CoSynch and supplemental estradiol cypionate (ECP) on reproductive responses of lactating dairy cows ${ }^{1}$

\begin{tabular}{|c|c|c|c|c|c|c|c|}
\hline Item & \multicolumn{2}{|c|}{ CoSynch 48} & \multicolumn{2}{|c|}{ CoSynch 72} & \multicolumn{3}{|c|}{$P$-value ${ }^{2}$} \\
\hline & & - $\%$ & & & & & \\
\hline Cyclic $^{3}$ & $76.6(187 / 244)$ & $69.4(168 / 242)$ & $69.9(167 / 239)$ & $73.6(181 / 246)$ & 0.67 & 0.45 & 0.03 \\
\hline Detected estrus ${ }^{4}$ & $33.1(80 / 242)$ & $59.8(146 / 244)$ & $49.6(122 / 246)$ & $79.9(191 / 239)$ & $<0.0001$ & $<0.0001$ & 0.35 \\
\hline Short-cycling ${ }^{5}$ & $5.8(14 / 240)$ & $6.6(16 / 243)$ & $3.3(8 / 245)$ & $5.4(13 / 239)$ & 0.17 & 0.28 & 0.71 \\
\hline d 68 & $39.2(95 / 242)$ & $44.7(109 / 244)$ & $44.1(108 / 245)$ & $43.1(103 / 239)$ & 0.41 & 0.14 & 0.37 \\
\hline Pregnancy loss & $5.0(5 / 100)$ & $4.4(5 / 114)$ & $2.7(3 / 111)$ & $1.9(2 / 105)$ & 0.15 & 0.97 & 0.79 \\
\hline AI interval, ${ }^{6} \mathrm{~d}$ & $25.6 \pm 1.1$ & $25.2 \pm 1.1$ & $27.0 \pm 1.1$ & $27.0 \pm 1.0$ & 0.10 & 0.86 & 0.85 \\
\hline
\end{tabular}

${ }^{1}$ All cows received 1 injection of $25 \mathrm{mg}$ of $\mathrm{PGF}_{2 \alpha}$ on $\mathrm{d} 37$ and 51 postpartum, and the CoSynch was initiated $13 \mathrm{~d}$ later. CoSynch $48=$ injection of $100 \mu \mathrm{g}$ of GnRH i.m. and timed AI $48 \mathrm{~h}$ after $\mathrm{PGF}_{2 a}$ of CoSynch; CoSynch $72=$ injection of $100 \mu \mathrm{g}$ of $\mathrm{GnRH}$ i.m. and timed AI $72 \mathrm{~h}$ after $\mathrm{PGF}_{2 \alpha}$ of CoSynch; ECP = injection of $1 \mathrm{mg}$ of estradiol cypionate i.m. given $24 \mathrm{~h}$ after $\mathrm{PGF}_{2 \alpha}$ of CoSynch.

${ }^{2}$ CoSynch $=$ effect of CoSynch $(48$ vs. $72 \mathrm{~h}) ; \mathrm{ECP}=$ effect of ECP $(\mathrm{ECP}$ vs. no ECP); CoSynch $\times$ ECP = interaction between CoSynch and ECP.

${ }^{3}$ Cows were classified as cyclic when progesterone concentration in plasma was $\geq 1 \mathrm{ng} / \mathrm{mL}$ in at least 1 of 2 sampling days at 57 and 64 DIM. ${ }^{4}$ Cows were detected in estrus based on the removal of tail chalk during $72 \mathrm{~h}$ after the injection of $\mathrm{PGF}_{2 \mathrm{a}}$ of the CoSynch.

${ }^{5}$ Cows returning to estrus between 5 and $17 \mathrm{~d}$ after timed AI.

${ }^{6}$ Interval between the first and second postpartum AI includes all nonpregnant cows reinseminated upon diagnosis of spontaneous estrus before pregnancy diagnosis $40 \mathrm{~d}$ after timed AI. 


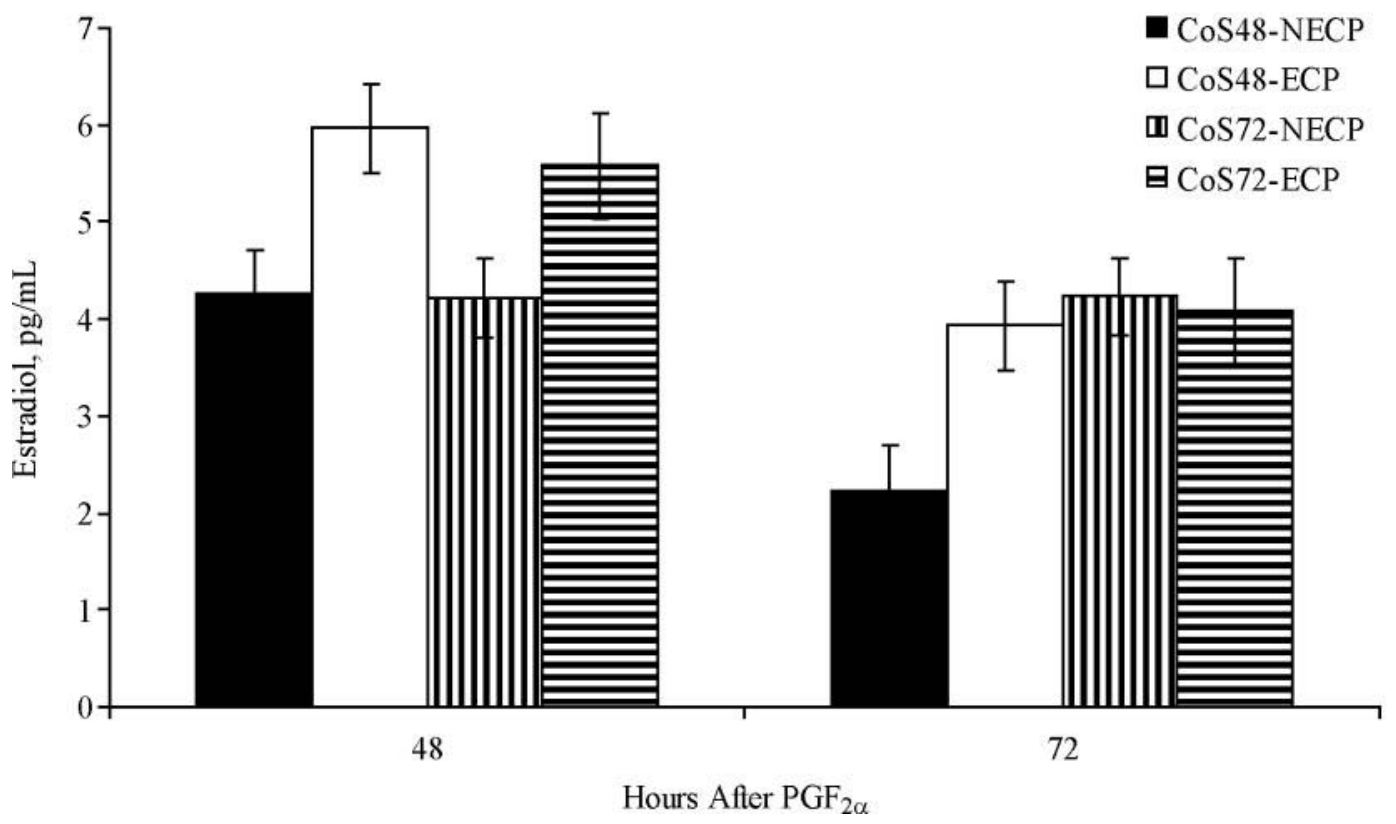

Figure 2. Plasma estradiol concentrations at 48 and $72 \mathrm{~h}$ after induction of luteolysis with $\mathrm{PGF}_{2 \alpha}$ in the CoSynch protocols $(24$ and $48 \mathrm{~h}$ after estradiol cypionate injection for CoS48-ECP and CoS72-ECP). All cows received 2 injections of $25 \mathrm{mg}$ of $\mathrm{PGF} \mathrm{F}_{2 \alpha} 14 \mathrm{~d}$ apart, with the second injection given $13 \mathrm{~d}$ before initiating one of the 4 treatments. Treatments were CoSynch $48 \mathrm{~h}$ without estradiol cypionate (CoS48-NECP, $\mathrm{n}=27$; black bars); CoSynch $48 \mathrm{~h}$ with estradiol cypionate (CoS48-ECP, $\mathrm{n}=28$; white bars $)$; CoSynch $72 \mathrm{~h}$ without ECP $($ CoS72-NECP, $\mathrm{n}=$ 39 ; bars with vertical crosshatch); CoSynch $72 \mathrm{~h}$ with ECP (CoS72-ECP, $\mathrm{n}=29$; bars with horizontal crosshatch). Effect of CoSynch: $P=0.29$; ECP: $P=0.005$; interaction between CoSynch and ECP: $P=0.18$; hour: $P<0.001$; interaction between CoSynch and hour: $P=0.007$; interaction between ECP and hour: $P=0.11$; and interaction between CoSynch and ECP and hour: $P=0.11$.

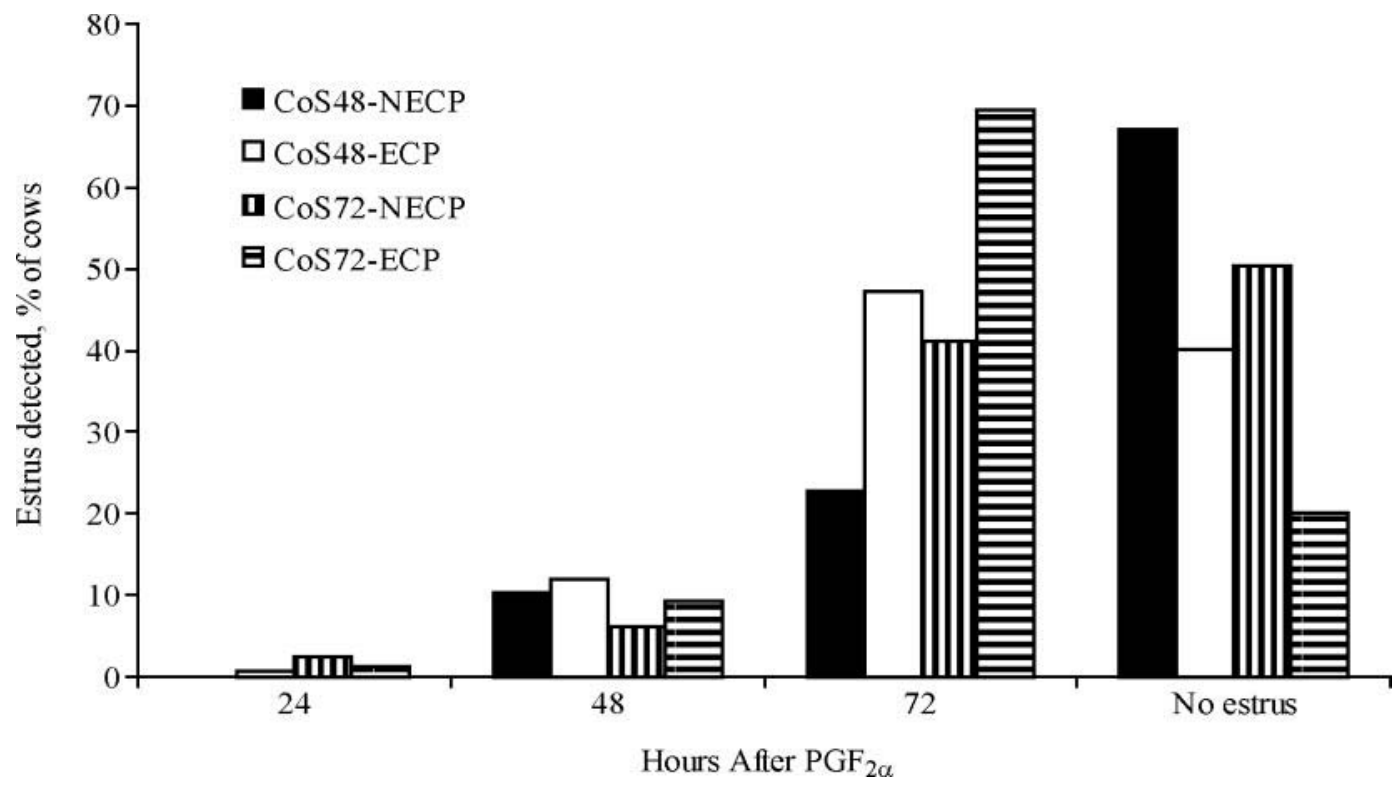

Figure 3. Proportion of cows detected in estrus within $72 \mathrm{~h}$ of induction of luteolysis with $\mathrm{PGF}_{2 \alpha}$ in the CoSynch protocols. All cows received 2 injections of $25 \mathrm{mg}$ of $\mathrm{PGF}_{2 \alpha} 14 \mathrm{~d}$ apart, with the second injection given $13 \mathrm{~d}$ before initiating one of the 4 treatments. Treatments were CoSynch $48 \mathrm{~h}$ without estradiol cypionate (CoS48-NECP; black bars); CoSynch $48 \mathrm{~h}$ with estradiol cypionate (CoS48-ECP; white bars); CoSynch $72 \mathrm{~h}$ without ECP (CoS72-NECP; bars with vertical crosshatch); CoSynch $72 \mathrm{~h}$ with ECP (CoS72-ECP; bars with horizontal crosshatch). At $24 \mathrm{~h}$, effect of CoSynch: $P=0.06$ and of ECP: $P=0.76$. At $48 \mathrm{~h}$, effect of CoSynch: $P=0.08$; ECP: $P=0.17$; interaction between CoSynch and ECP: $P=0.70$. At 72 h, effect of CoSynch: $P<0.001$; ECP: $P<0.001$; and interaction between CoSynch and ECP: $P=0.44$. 
Table 2. Effect of detection of estrus at timed AI on reproductive responses of lactating dairy cows receiving CoSynch at 48 or $72 \mathrm{~h}$ and supplemented or not with estradiol cypionate (ECP) ${ }^{1}$

\begin{tabular}{|c|c|c|c|c|c|c|c|c|c|}
\hline Item & \multicolumn{4}{|c|}{ CoSynch 48} & \multicolumn{4}{|c|}{ CoSynch 72} & $P$-value \\
\hline Cows, $\mathrm{n}$ & 80 & 162 & 146 & 98 & 122 & 124 & 191 & 48 & \\
\hline Short-cycling, ${ }^{4} \%$ & 2.5 & 7.5 & 3.5 & 11.2 & 1.6 & 4.9 & 0.5 & 25.0 & 0.0001 \\
\hline Pregnant, \% & & & & & & & & & \\
\hline Pregnancy loss, \% & 7.1 & 3.5 & 3.7 & 6.3 & 1.3 & 5.6 & 1.0 & 11.1 & 0.35 \\
\hline
\end{tabular}

${ }^{1}$ All cows received 1 injection of $25 \mathrm{mg}$ of $\mathrm{PGF}_{2 \alpha}$ on $\mathrm{d} 37$ and 51 postpartum, and the CoSynch was initiated $13 \mathrm{~d}$ later. CoSynch $48=$ injection of $100 \mu \mathrm{g}$ of GnRH i.m. and timed AI $48 \mathrm{~h}$ after $\mathrm{PGF}_{2 a}$ of CoSynch; CoSynch $72=$ injection of $100 \mu \mathrm{g}$ of $\mathrm{GnRH}$ i.m. and timed AI $72 \mathrm{~h}$ after $\mathrm{PGF}_{2 \alpha}$ of CoSynch; ECP = injection of $1 \mathrm{mg}$ of estradiol cypionate i.m. given $24 \mathrm{~h}$ after $\mathrm{PGF}_{2 \alpha}$ of CoSynch.

${ }^{2}$ Cows were detected in estrus based on the removal of tail chalk during $72 \mathrm{~h}$ after the injection of PGF $\mathrm{F}_{2 \alpha}$ of the CoSynch.

${ }^{3}$ Effect of estrus. No interactions $(P>0.10)$ between CoSynch and estrus or ECP and display of estrus or CoSynch and ECP and display of estrus were observed for short-cycling, pregnancy per AI, and pregnancy loss.

${ }^{4}$ Cows returning to estrus between 5 and $17 \mathrm{~d}$ after timed AI.

pregnancy per AI compared with multiparous cows (46.9 vs. $31.9 \%)$. Milk yield in the first $60 \mathrm{~d}$ postpartum tended $(P=0.09)$ to influence pregnancy on $\mathrm{d} 40$, and cows within the greatest quartile of milk yield were 1.6 times more $(P<0.05)$ likely to become pregnant than those in the lowest quartile. Pregnancy per AI for cows in milk yield quartiles $1,2,3$, and 4 was, respectively, $39.9,42.6,46.4$, and 48.7\%. Similar responses were observed for pregnancy per AI on d 68 after AI. A total of 15 cows lost their pregnancies between 40 and $68 \mathrm{~d}$ of gestation, resulting in an overall pregnancy loss of $3.5 \%(15 / 430)$. None of the predictors in the statistical model influenced pregnancy loss.

Cows not observed in estrus AI were 5.8 times more $(\mathrm{AOR}=5.76 ; 95 \% \mathrm{CI}=2.83,11.72)$ likely to experience short-cycling than cows in estrus at AI (9.5 vs. 1.9\%; $P<0.0001$ ), and responses were observed regardless of CoSynch and supplemental ECP (Table 2). Cows displaying estrus at AI had greater $(P<0.0001)$ pregnancy per AI at 40 (54.7 vs. 31.5\%) and 68 (53.3 vs. $31.5 \%) \mathrm{d}$ after insemination. No interaction between estrus and treatments was observed for pregnancy per AI. Pregnancy loss did not differ for cows in estrus $(2.7 \%)$ or not $(5.2 \%)$ at AI.

When ovulatory responses were evaluated, a greater $(P=0.05)$ proportion of CoS72 than CoS48 cows $(95.7$ vs. $87.3 \%)$ had a CL at the administration of $\mathrm{PGF}_{2 a}$ preceding timed AI (Table 3). Incidences of ovulation and double ovulation were similar for all treatments. Diameter of ovulatory follicle was not influenced by time of AI, but administration of ECP resulted in ovulation of a slightly smaller $(P=0.05)$ follicle. For cows experiencing double ovulation, the diameter of the second largest ovulatory follicle did not differ among treatments. Concentration of progesterone on $\mathrm{d} 7 \mathrm{after}$ timed AI did not differ among treatments.

A greater $(P=0.02)$ proportion of cows that displayed estrus ovulated after the timed AI, but incidences of double ovulation were similar when all cows or only ovulatory cows were considered (Table 4). The diameter of the dominant follicle did not differ between cows in estrus and those not in estrus. Likewise, the diameter of the second largest follicle for cows with double ovulation was similar between cows in estrus and those not in estrus. Cows displaying estrus had greater $(P=$ 0.04) concentrations of estradiol at $48 \mathrm{~h}$ after induced luteolysis and of progesterone on d 7 after timed AI. Increased estradiol for cows in estrus was observed despite ECP treatment and timing of GnRH injection, because no interaction between treatment and estrus was observed for plasma estradiol.

Diameter of ovulatory follicle did not $(P=0.17)$ influence pregnancy at d 40 [follicle $<15 \mathrm{~mm}=29.4(5 / 17) \mathrm{vs}$. follicle $\geq 15 \mathrm{~mm}=47.1 \%(48 / 102)]$, but cows experiencing double ovulation tended $(P=0.08)$ to have greater pregnancy per AI [63.2\% (12/19) vs. 41.9\% (44/105)]. Cows with greater concentration of progesterone on $d 7$ after timed AI had increased $(P<0.001)$ pregnancy per $\mathrm{AI}$ at 40 [low $=19.4 \%(7 / 36) ;$ moderate $=44.1 \%(49 / 11)$; and high $=64.1 \%(24 / 38)]$ and $68 \mathrm{~d}$ (low $=19.4 \%(7 / 36)$; moderate $=44.1 \%(49 / 111) ;$ and high $=63.2 \%(24 / 38)]$ after timed AI.

\section{DISCUSSION}

Timed AI programs are frequently used for reproductive management of dairy cattle to assure insemination of eligible cows (Caraviello et al., 2006). One of the most 
Table 3. Effect of CoSynch and supplemental estradiol cypionate (ECP) on ovulatory responses and progesterone concentration ${ }^{1}$

\begin{tabular}{|c|c|c|c|c|c|c|c|}
\hline \multirow[b]{2}{*}{ Item } & \multicolumn{2}{|c|}{ CoSynch 48} & \multicolumn{2}{|c|}{ CoSynch 72} & \multicolumn{3}{|c|}{$P$-value ${ }^{2}$} \\
\hline & No ECP & ECP & No ECP & ECP & CoSynch & ECP & $\begin{array}{c}\text { CoSynch } \\
\times \text { ECP }\end{array}$ \\
\hline & & - $\%$ & & & & & \\
\hline \multirow{2}{*}{$\begin{array}{l}\text { Corpus luteum at } \mathrm{PGF}_{2 \alpha} \\
\text { Ovulation }\end{array}$} & $85.2(23 / 27)$ & $89.3(25 / 28)$ & $97.4(38 / 39)$ & $96.6(28 / 29)$ & 0.05 & 0.98 & 0.76 \\
\hline & $81.5(22 / 27)$ & $82.1(23 / 28)$ & $87.2(34 / 39)$ & $86.2(25 / 29)$ & 0.55 & 0.71 & 0.86 \\
\hline \multicolumn{8}{|l|}{ Ovulatory follicle diameter, $\mathrm{mm}$} \\
\hline Largest follicle & $18.7 \pm 0.8$ & $18.0 \pm 0.7$ & $19.7 \pm 0.6$ & $17.7 \pm 0.7$ & 0.53 & 0.05 & 0.29 \\
\hline Second largest (double ovulation) & $10.2 \pm 3.8$ & $11.2 \pm 2.6$ & $14.6 \pm 2.4$ & $11.3 \pm 2.6$ & 0.53 & 0.63 & 0.36 \\
\hline Progesterone $\mathrm{d} 7, \mathrm{ng} / \mathrm{mL}$ & $1.48 \pm 0.10$ & $1.35 \pm 0.10$ & $1.41 \pm 0.08$ & $1.32 \pm 0.09$ & 0.65 & 0.21 & 0.79 \\
\hline
\end{tabular}

${ }^{1}$ All cows received 1 injection of $25 \mathrm{mg}$ of $\mathrm{PGF}_{2 \mathrm{a}}$ on $\mathrm{d} 37$ and 51 postpartum, and the CoSynch was initiated $13 \mathrm{~d}$ later. CoSynch $48=$ injection of $100 \mu \mathrm{g}$ of $\mathrm{GnRH}$ i.m. and timed $\mathrm{AI} 48 \mathrm{~h}$ after $\mathrm{PGF}_{2 \mathrm{a}}$ of CoSynch; CoSynch 72 = injection of $100 \mu \mathrm{g}$ of GnRH i.m. and timed AI $72 \mathrm{~h}$ after $\mathrm{PGF}_{2 \alpha}$ of CoSynch; ECP = injection of $1 \mathrm{mg}$ of estradiol cypionate i.m. given $24 \mathrm{~h}$ after $\mathrm{PGF}_{2 \alpha}$ of CoSynch.

${ }^{2}$ CoSynch $=$ effect of CoSynch $(48$ vs. 72 h); ECP = effect of ECP (ECP vs. no ECP); CoSynch $\times$ ECP = interaction between CoSynch and ECP.

commonly used timed AI program in lactating dairy cattle is the Ovsynch protocol (Pursley et al., 1995), which was initially designed to mimic the natural proestrus and have induced ovulation 8 to $16 \mathrm{~h}$ before AI. In contrast, many producers are reluctant to manage cows twice daily, particularly in large dairy herds, in which cows are restrained for reproductive work only once daily. Because of that, others have evaluated different timings of induced ovulation with $\mathrm{GnRH}$ relative to AI in lactating dairy cows (Pursley et al., 1998; Peters and Pursley, 2003; Portaluppi and Stevenson, 2005; Sterry et al., 2007; Brusveen et al., 2008).

Pursley et al. (1998) were the first to evaluate the effect of interval between the GnRH and time of AI in lactating dairy cows. They observed decreased pregnancy per AI in cows inseminated $32 \mathrm{~h}$ after the GnRH injection, whereas maximum percentage of cows pregnant and calving was obtained when timed AI was performed $16 \mathrm{~h}$ after the final GnRH injection of the Ovsynch. To avoid handling lactating dairy cows twice in the same day, Portaluppi and Stevenson (2005) evaluated modifications of the Ovsynch and observed a tendency for increased proportion of cows calving when they received the final GnRH and timed AI at $72 \mathrm{~h}$ compared with GnRH and timed AI $48 \mathrm{~h}$ after the $\mathrm{PGF}_{2 \alpha}$. The same authors (Portaluppi and Stevenson, 2005) also observed decreased pregnancy loss for cows that received the final GnRH and timed AI at 72 $\mathrm{h}$ compared with cows subjected to the CoS48. When cows were subjected to a presynchronized estrous synchronization protocol and inseminated upon detection of estrus, the distribution of estruses after induced luteolysis resulted in a mean $( \pm \mathrm{SD})$ and median interval of $3.2 \pm 1.0$ and $3.0 \mathrm{~d}$, respectively (Cerri et al., 2004). Of the 258 cows observed in estrus, the proportions of cows that displayed estrus on $\mathrm{d} 1,2,3,4$, and 5 after $\mathrm{PGF}_{2 \mathrm{a}}$ were $2.4,12.2,52.4,22.8$, and $7.1 \%$, respectively (Cerri et al., 2004). In the same experiment (Cerri et al., 2004), when cows received ECP $24 \mathrm{~h}$ after $\mathrm{PGF}_{2 \mathrm{a}}$, estrus distribution for the 310 cows observed in estrus was $7.1,26.5$, and $66.5 \%$ for d 1,2 , and 3 after $\mathrm{PGF}_{2 \alpha}$, respectively. Therefore, $3 \mathrm{~d}$ after a presynchro-

Table 4. Effect of display of estrus on ovarian responses of dairy cows ${ }^{1}$

\begin{tabular}{|c|c|c|c|c|}
\hline Item & No estrus & Estrus & $\operatorname{AOR}(95 \% \mathrm{CI})^{2}$ & $P$-value \\
\hline \multicolumn{5}{|l|}{ Double ovulation, \% } \\
\hline All cows & $11.8(9 / 76)$ & $19.2(9 / 47)$ & $1.45(0.46$ to 4.59$)$ & 0.45 \\
\hline \multicolumn{5}{|l|}{ Ovulatory follicle, $\mathrm{mm}$} \\
\hline Largest follicle & $18.2 \pm 0.5$ & $18.7 \pm 0.7$ & - & 0.51 \\
\hline Second largest (double ovulation) & $16.2 \pm 2.3$ & $17.8 \pm 4.8$ & - & 0.75 \\
\hline
\end{tabular}

${ }^{1}$ Cows were detected in estrus based on the removal of tail chalk during $72 \mathrm{~h}$ after the injection of $\mathrm{PGF}_{2 a}$ of the CoSynch.

${ }^{2} \mathrm{AOR}=$ adjusted odds ratio; $95 \% \mathrm{CI}=95 \%$ confidence interval. Cows not detected in estrus were the reference for comparison. 
nized GnRH-PGF $2 a$ program is when most cows are observed in estrus. Similarly, the current study also demonstrated that the majority of cows in estrus were observed at $72 \mathrm{~h}$ after the injection of $\mathrm{PGF}_{2 \alpha}$ (Figure 3). It is important to indicate that detection of estrus was limited to the first $3 \mathrm{~d}$ after induced luteolysis, which might have underestimated display of estrus, because some cows might have exhibited estrus after $72 \mathrm{~h}$.

Time of ovulation in dairy cows after the initial display of estrus is approximately $28 \mathrm{~h}$ (Walker et al., 1996), which is similar to that observed in cows induced to ovulate with GnRH in the Ovsynch protocol (Pursley et al., 1995; Stevenson et al., 2004). When cows were inseminated after detection of estrus, maximum pregnancy per AI was observed in cows inseminated between 4 and $16 \mathrm{~h}$ after the onset of estrus (Dransfield et al., 1998). Pregnancy was particularly poor when cows were inseminated too late relative to onset of estrus, which has been suggested to be related to impaired oocyte quality (Saacke et al., 2000).

The initial hypothesis of the current study was that delaying the time of induced ovulation and AI from 48 to $72 \mathrm{~h}$ in a presynchronized timed AI protocol would enhance pregnancy per AI because of extended proestrus resulting in extended exposure to increased concentrations of estradiol and display of estrus. In contrast, GnRH injection and timed insemination of cows at either 48 or $72 \mathrm{~h}$ after luteolysis resulted in similar pregnancy per AI, which contrasts with findings by Portaluppi and Stevenson (2005). Similar to the present findings, others also observed lack of differences in pregnancy per AI to first and subsequent inseminations when cows were subjected to the CoS48 or CoS72 (Sterry et al., 2007; Brusveen et al., 2008).

One of the rationales for extending proestrus was to optimize synchronization of ovulation with the expected time when most cows display estrus after luteolysis. This might be critically important when cows are induced to ovulate and inseminated at the same time. It has been demonstrated that limiting the proestrus to less than $36 \mathrm{~h}$ in the Ovsynch protocol resulted in ovulation of small follicles and decreased pregnancy per AI in dairy cows in part because of increased incidence of post-AI short luteal phases (Peters and Pursley, 2003). Although the duration of the luteal phase after timed AI was not evaluated in the current study, the proportion of cows returning to estrus prematurely was not affected by timing of GnRH injection, which suggests that a proestrus of $48 \mathrm{~h}$ was sufficient to prevent shortcycling in dairy cows.

Previously, replacing the final GnRH with $1 \mathrm{mg}$ of ECP in a timed AI protocol resulted in similar pregnancy per AI (Pancarci et al., 2002). On the other hand, inducing ovulation with $1 \mathrm{mg}$ of ECP to allow for timed
$\mathrm{AI}$ increased pregnancy per $\mathrm{AI}$ in dairy cows compared with that of cows inseminated after a synchronized estrus (Cerri et al., 2004). Improvements in pregnancy per AI were suggested to be caused by increased exposure to estradiol during proestrus, which could have improved oocyte fertilization or better primed the uterus for the subsequent luteal phase, which is important for induction of endometrial progesterone receptors (Zelinsky and Stormshak, 1981), and to avoid short-cycling (Kieborz-Loos et al., 2003). The highproducing dairy cow may lack sufficient concentrations of estradiol in blood to induce estrus, ovulation, and uterine priming because of the inherently extensive steroid metabolism and clearance (Wiltbank et al., 2006). Sartori et al. (2002) demonstrated that heifers exhibited significantly greater peak estradiol concentrations compared with lactating cows, although cows had larger ovulatory follicles. Therefore, it is possible that supplementation with estradiol during proestrus might benefit fertility of high-producing dairy cows, particularly in synchronization protocols that might limit exposure to follicular estradiol.

Two experiments have tested the hypothesis that supplemental estradiol might benefit fertility of dairy cows in timed AI protocols. In the first, cows received $0.25 \mathrm{mg}$ of ECP at the same time of the final GnRH in the Ovsynch protocol, and although serum estradiol concentrations increased in ECP-supplemented cows, pregnancy per AI remained unaltered (Sellars et al., 2006). Recently, cows received $1 \mathrm{mg}$ of estradiol-178 8 $\mathrm{h}$ before the final GnRH in the Ovsynch program in an attempt to better mimic the natural increase in estradiol in cows that, if not treated with $\mathrm{GnRH}$, would likely display signs of estrus (Souza et al., 2007). It was demonstrated that supplemental estradiol did not improve overall pregnancy per AI, but cows ovulating follicles of intermediate diameter and of low BCS benefited from supplemental estradiol (Souza et al., 2007). Administration of $0.5 \mathrm{mg}$ of ECP $24 \mathrm{~h}$ before the final GnRH in the Ovsynch protocol decreased the proportion of oocytes and embryos without accessory spermatozoa compared with the Ovsynch alone, but it did not improve oocyte fertilization (Cerri et al., accepted). Therefore, in cows with at least $48 \mathrm{~h}$ of proestrus, it is unlikely that supplemental estradiol as ECP benefits fertility. The results from the current study corroborate with those of Sellars et al. (2006) and do not support the initial hypothesis that supplemental ECP would improve pregnancy per AI in cows induced to ovulate with $\mathrm{GnRH}$ in timed AI protocols, despite increased display of estrus. Although ECP increased estradiol concentrations in the subsequent $48 \mathrm{~h}$ after treatment, an increment of that magnitude might not be sufficient to improve pregnancy. 
Display of estrus was influenced by treatments, $\mathrm{BCS}$ at $\mathrm{AI}$, and parity, and cows that displayed estrus had greater pregnancy per AI. The positive effect of detected estrus on pregnancy when timed AI protocols utilize GnRH or ECP to induce ovulation has been previously observed (Pancarci et al., 2002; Cerri et al., 2004; Portaluppi and Stevenson, 2005). It is interesting to note that display of estrus improved pregnancy per AI independent of ECP or timing of GnRH injection. Furthermore, cows detected in estrus had increased concentrations of estradiol at $48 \mathrm{~h}$ after luteolysis, immediately before $\mathrm{GnRH}$-induced ovulation. This increase in estradiol concentration was observed in both ECP and NECP cows. Collectively, these data suggest that endogenous estradiol is critical to pregnancy in timed AI protocols.

A possible reason for increased pregnancy per AI in cows displaying estrus is the improved incidence of ovulation observed in the current study, which has also been shown previously (Galvão et al., 2004). Furthermore, cows in estrus had a greater concentration of progesterone on $\mathrm{d} 7$ after $\mathrm{AI}$ than those not in estrus, and display of estrus decreased the proportion of cows that experienced short-cycling. These differences between cows displaying or not estrus at timed AI support the concept that expression of estrus improves fertility of dairy cattle subjected to timed AI programs. Also, benefits of expression of estrus to pregnancy might be associated with more estrogenic follicles that result in improved synchronization and luteal function, and decreased short-cycling, all of which favor pregnancy. In fact, the current study observed that synchronized cows and those with a greater concentration of progesterone on $\mathrm{d} 7$ after AI were more likely to be pregnant at 40 and $68 \mathrm{~d}$ after $\mathrm{AI}$, demonstrating the importance of timing of ovulation and increased progesterone concentration for pregnancy.

Adequate exposure to estradiol during proestrus is critical to pregnancy, because it is associated with expression of endometrial progesterone receptors (Zelinsky and Stormshak, 1981). Lack of progesterone receptor expression because of insufficient estradiol priming of the uterus may lead to premature luteolysis. This might explain the increased risk for short-cycling in cows not observed in estrus. Kieborz-Loos et al. (2003) used ovariectomized cows to demonstrate failure of progesterone treatment to inhibit oxytocin-induced release of uterine prostaglandins when estradiol priming was not provided. Furthermore, the concentration of preovulatory estradiol was inversely correlated with endometrial expression of oxytocin receptors that mediate prostaglandin release (Kieborz-Loos et al., 2003). Therefore, adequate exposure to estradiol during proestrus is expected to minimize short-cycling and improve fertility. This might further explain the beneficial effects of display of estrus on fertility of cows observed in the current study.

\section{CONCLUSIONS}

Lactating dairy cows subjected to presynchronized timed AI protocols with varying duration of proestrus before GnRH, in which AI was performed at the same time as GnRH injection, experienced similar pregnancy per AI. Furthermore, although supplementation with estradiol as ECP increased estradiol concentrations, it did not influence pregnancy per AI or pregnancy loss of dairy cows. It is noteworthy that extending the period of proestrus and supplementing cows with ECP increased display of estrus primarily at $72 \mathrm{~h}$ after $\mathrm{PGF}_{2 \alpha}$ but did not improve fertility. Cows displaying estrus had increased concentrations of estradiol during proestrus, increased incidence of ovulation, increased concentrations of progesterone $7 \mathrm{~d}$ after timed AI, and fewer short cycles after breeding. These effects resulted in cows that displayed estrus being 2.5 times more likely to become pregnant than those not expressing estrus. Although the current study did not observe differences in pregnancy by extending the proestrus or supplementing estradiol, it clearly demonstrated that timed AI programs should be designed to increase expression of estrus either at the day of timed AI or after as it is related to increased fertility.

\section{ACKNOWLEDGMENTS}

We wish to thank the owner and staff of River Ranch Farms (Hanford, CA) for use of their cows and facilities. The assistance of M. F. Sheley (University of California Davis), R. L. A. Cerri (University of Florida), and R. Bisinotto (University of Florida) during the study is appreciated. Our gratitude is extended to Merial and Pfizer Animal Health for providing the Cystorelin and Lutalyse, respectively, used in this study. This research was partially supported by National Research Initiative Competitive Grant no. 2004-35203-14137 from the USDA Cooperative State Research, Education, and Extension Service.

\section{REFERENCES}

Brusveen, D. J., A. P. Cunha, C. D. Silva, P. M. Cunha, R. A. Sterry, E P. B. Silva, J. N. Guenther, and M. C. Wiltbank. 2008. Altering the time of the second gonadotropin-releasing hormone injection and artificial insemination (AI) during Ovsynch affects pregnancies per AI in lactating dairy cows. J. Dairy Sci. 91:1044-1052.

Caraviello, D. Z., K. A. Weigel, P. M. Fricke, M. C. Wiltbank, M. J. Florent, N. B. Cook, K. V. Nordlund, N. R. Zwald, and C. L. Rawson. 2006. Survey of management practices on reproductive performance of dairy cattle on large US commercial farms. J. Dairy Sci. 89:4723-4735. 
Cerri, R. L. A., H. M. Rutigliano, R. C. Chebel, and J. E. P. Santos. Period of dominance of the ovulatory follicle influence embryo quality in lactating dairy cows. Reproduction (accepted)

Cerri, R. L. A., J. E. P. Santos, S. O. Juchem, K. N. Galvão, and R. C. Chebel. 2004. Timed artificial insemination with estradiol cypionate or insemination at estrus in high-producing dairy cows. J. Dairy Sci. 87:3704-3715.

Dransfield, M. B. G., R. L. Nebel, R. E. Pearson, and L. D. Warnick. 1998. Timing of insemination for dairy cows identified in estrus by a radiotelemetric estrus detection system. J. Dairy Sci. $81: 1874-1882$

Elanco Animal Health. 1996. Body condition scoring in dairy cattle. Elanco Animal Health Bulletin AI 8478. Elanco Animal Health, Greenfield, IN.

Ferguson, J. D., D. T. Galligan, and N. Thomsen. 1994. Principal descriptors of body condition score in Holstein cows. J. Dairy Sci. 77:2695-2703

Galvão, K. N., J. E. P. Santos, S. O. Juchem, R. L. A. Cerri, A. C. Coscioni, and M. Villaseňor. 2004. Effect of addition of a progesterone intravaginal insert to a timed insemination protocol using estradiol cypionate on ovulation rate, pregnancy rate, and late embryonic loss in lactating dairy cows. J. Anim. Sci. 82:3508-3517.

Kieborz-Loos, K. R., H. A. Garverick, D. H. Keisler, S. A. Hamilton, B. E. Salfen, R. S. Youngquist, and M. F. Smith. 2003. Oxytocininduced secretion of prostaglandin $\mathrm{F}_{2 \alpha}$ in postpartum beef cows: Effects of progesterone and estradiol-17B treatment. J. Anim. Sci. 81:1830-1836.

Moreira, F., C. Orlandi, C. A. Risco, R. Mattos, F. Lopes, and W. W. Thatcher. 2001. Effects of presynchronization and bovine somatotropin on pregnancy rates to a time artificial insemination protocol in lactating dairy cows. J. Dairy Sci. 84:1646-1659.

NRC. 2001. Nutrient Requirements of Dairy Cattle. 7th rev. ed. Natl. Acad. Sci., Washington, DC.

Pancarci, S. M., E. R. Jordan, C. A. Risco, M. J. Schouten, F. L. Lopes, F. Moreira, and W. W. Thatcher. 2002. Use of estradiol cypionate in a presynchronized timed artificial insemination program for lactating dairy cattle. J. Dairy Sci. 85:122-131.

Perry, R. C., L. R. Corah, G. H. Kiracofe, J. S. Stevenson, and W. E. Beal. 1991. Endocrine changes and ultrasonography of ovaries in suckled beef cows during resumption of postpartum estrous cycles. J. Anim. Sci. 69:2548-2555.

Peters, M. W., and J. R. Pursley. 2003. Timing of final GnRH of the Ovsynch protocol affects ovulatory follicle size, subsequent luteal function, and fertility in dairy cows. Theriogenology 60:11971204

Portaluppi, M. A., and J. S. Stevenson. 2005. Pregnancy rates in lactating dairy cows after presynchronization of estrous cycles and variations of the Ovsynch protocol. J. Dairy Sci. 88:914921.

Pursley, J. R., M. O. Mee, and M. C. Wiltbank. 1995. Synchronization of ovulation in dairy cows using $\mathrm{PGF}_{2 \alpha}$ and $\mathrm{GnRH}$. Theriogenology 44:915-923.

Pursley, J. R., R. W. Silcox, and M. C. Wiltbank. 1998. Effect of time of artificial insemination on pregnancy rates, calving rates, pregnancy loss, and gender ratio after synchronization of ovulation in lactating dairy cows. J. Dairy Sci. 81:2139-2144.

Saacke, R. G., J. C. Dalton, S. Nadir, R. L. Nebel, and J. H. Bame. 2000. Relationship of seminal traits and insemination time to fertilization rate and embryo quality. Anim. Reprod. Sci. 6061:663-677.

Sartori, R., G. J. M. Rosa, and M. C. Wiltbank. 2002. Ovarian structures and circulating steroids in heifers and lactating cows in summer and lactating and dry cows in winter. J. Dairy Sci. 85:2813-2822.

Sellars, C. B., J. C. Dalton, R. Manzo, J. Day, and A. Ahmadzadeh. 2006. Time and incidence of ovulation and conception rates after incorporating estradiol cypionate into a timed artificial insemination protocol. J. Dairy Sci. 89:620-626.

Souza, A. H., A. Gumen, E. P. B. Silva, A. P. Cunha, J. N. Guenther, C. M. Peto, D. Z. Caraviello, and M. C. Wiltbank. 2007. Supplementation with estradiol-178 before the last gonadotropinreleasing hormone injection of the Ovsynch protocol in lactating dairy cows. J. Dairy Sci. 90:4623-4634.

Sterry, R. A., P. J. Jardon, and P. M. Fricke. 2007. Effect of timing of Cosynch on fertility of lactating Holstein cows after first postpartum and Resynch timed-AI services. Theriogenology 67:1211-1216.

Stevenson, J. S., S. M. Tiffany, and M. C. Lucy. 2004. Use of estradiol cypionate as a substitute for $\mathrm{GnRH}$ in protocols for synchronizing ovulation in dairy cattle. J. Dairy Sci. 87:3289-3305.

Walker, W. L., R. L. Nebel, and M. L. McGilliard. 1996. Time of ovulation relative to mounting activity in dairy cattle. J. Dairy Sci. 79:1555-1561.

Wiltbank, M. C., H. Lopez, R. Sartori, S. Sangsritavong, and A. Gümen. 2006. Changes in reproductive physiology of lactating dairy cows due to elevated steroid metabolism. Theriogenology 65:17-29.

Zelinsky, M. B., and F. Stormshak. 1981. Temporal relationships between endometrial RNA polymerase activities and steroid hormone receptors following estradiol administration during the midluteal phase and of the ovine estrous cycle. Biol. Reprod. $24: 119-124$ 